\title{
Wake Encounter Analysis for a Closely Spaced Parallel Runway Paired Approach Simulation
}

\author{
Burnell T. McKissick ${ }^{1}$, Fernando J. Rico-Cusi ${ }^{2}$, Jennifer L. Murdoch ${ }^{3}$, \\ Rosa Oseguera-Lohr ${ }^{4}$, H. Paul Stough, III ${ }^{5}$, and Cornelius J. O'Connor ${ }^{6}$ \\ NASA Langley Research Center, Hampton, VA 23681-2199 \\ Hazari I. Syed ${ }^{7}$ \\ Raytheon Information Solutions, Hampton, VA 23681
}

\begin{abstract}
A Monte Carlo simulation of simultaneous approaches performed by two transport category aircraft from the final approach fix to a pair of closely spaced parallel runways was conducted to explore the aft boundary of the safe zone in which separation assurance and wake avoidance are provided. The simulation included variations in runway centerline separation, initial longitudinal spacing of the aircraft, crosswind speed, and aircraft speed during the approach. The data from the simulation showed that the majority of the wake encounters occurred near or over the runway and the aft boundaries of the safe zones were identified for all simulation conditions.
\end{abstract}

\section{Nomenclature}

\begin{tabular}{|c|c|c|}
\hline AOI & $=$ & area of interest \\
\hline APA & $=$ & AVOSS Prediction Algorithm \\
\hline AVOSS & $=$ & Aircraft VOrtex Spacing System \\
\hline CSPR & $=$ & Closely Spaced Parallel Runways \\
\hline$D$ & $=$ & distance from the runway far end of the vortex encounter \\
\hline EDR & $=$ & Eddy Dissipation Rate \\
\hline$f$ & $=$ & frequency estimate of the probability of a vortex encounter \\
\hline FAF & $=$ & Final Approach Fix \\
\hline$\Gamma$ & $=$ & vortex circulation when the vortex encounter occurred \\
\hline$H$ & $=$ & wake altitude, height above ground level at which the vortex encounter occurred \\
\hline IGE & $=$ & in ground effect \\
\hline ILS & $=$ & Instrument Landing System \\
\hline IMC & $=$ & Instrument Meteorological Conditions \\
\hline LDA/DME & $=$ & Localizer type Directional Aid/Distance Measuring Equipment \\
\hline LES & $=$ & large eddy simulation \\
\hline NASA & $=$ & National Aeronautics and Space Administration \\
\hline OGE & $=$ & out of ground effect \\
\hline Rlo & $=$ & relative longitudinal position between aircraft at the vortex encounter \\
\hline Rlt & $=$ & relative lateral position between aircraft at the vortex encounter \\
\hline$R v t$ & $=$ & relative vertical position between aircraft at the vortex encounter \\
\hline SFO & $=$ & San Francisco International Airport \\
\hline SOIA & & Simultaneous Offset Instrument Approach \\
\hline STL & & Lambert-St. Louis International Airport \\
\hline TASS & $=$ & Terminal Area Simulation System \\
\hline
\end{tabular}

${ }^{1}$ Mathematician, Crew Systems and Aviation Operations Branch, MS 156A.

${ }^{2}$ Senior Analyst, Aerospace Engineer, Aeronautics Systems Analysis Branch, MS 442.

${ }^{3}$ Research Psychologist, Crew Systems and Aviation Operations Branch, MS 156A.

${ }_{5}^{4}$ Aerospace Engineer, Aeronautics Systems Analysis Branch, MS 442, Senior Member.

${ }^{5}$ Senior Research Engineer, Crew Systems and Aviation Operations Branch, MS 152, Associate Fellow.

${ }^{6}$ Project Manager, NextGen Airportal Project, Aeronautics Research Directorate, MS 152.

${ }^{7}$ Senior Principal Analyst, Raytheon Information Solutions

American Institute of Aeronautics and Astronautics 


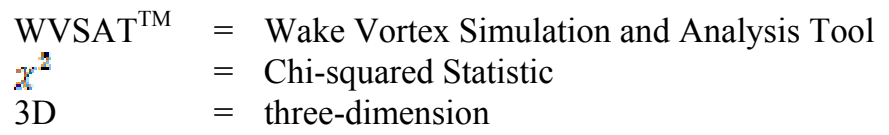

\section{Introduction}

In his 1999 paper entitled "Study of the Geometry of a Dependent Approach Procedure to Closely Spaced Parallel Runways," Hammer ${ }^{1}$ states that "[t]he loss of visual flight rules under instrument conditions results in a substantial loss of throughput to airports with very closely spaced parallel runways (less than $2500 \mathrm{ft}$ )." To address this loss of throughput during instrument meteorological conditions (IMC), United Airlines proposed a procedure for dependent approaches into San Francisco International Airport (SFO) during the mid-1990's ${ }^{2}$. This proposed use of paired approaches (i.e., approaches consisting of two aircraft flying closer to one another than current wake separation and collision avoidance standards allow) represented the first potential solution to the problem associated with a decrease in throughput to airports having closely spaced parallel runways (CSPRs), i.e. parallel runways separated by less than $4300 \mathrm{ft}$.

Since the introduction of dependent approaches at SFO, additional research efforts have led to the use of the localizer-type directional aid with distance measuring equipment (LDA/DME) approach (also referred to as the Simultaneous Offset Instrument Approach, SOIA) procedure at SFO and, subsequently, at Lambert-St. Louis International Airport (STL). To date, the LDA/DME approach serves as the only operational implementation of a paired approach procedure; however, there is renewed interest in this type of approach as a means for increasing arrival rates at busy airports, particularly in anticipation of predicted increases in air transport operations. Further investigations of the paired approach concept include the research of Landry and Pritchett ${ }^{3}$ which introduces the concept of a "safe zone" (i.e., "an area in which separation assurance and wake avoidance is provided") and the work of Bone, Olmos, and Mundra ${ }^{4}$ which discusses the preliminary development of a paired approach from an operational perspective.

As shown in Fig. 1, the wake free zone represents a region wherein the trailing aircraft safely avoids any wake vortex generated by the lead aircraft. Overconservatism in the delineation of the wake free zone adversely impacts potential airport throughput gains from closely-spaced parallel approaches. The research endeavor described in this paper uses a Monte Carlo simulation to gauge the impact of runway separation, aircraft longitudinal spacing, crosswind speed, and relative speeds of the two airplanes on the wake-freezone boundary.

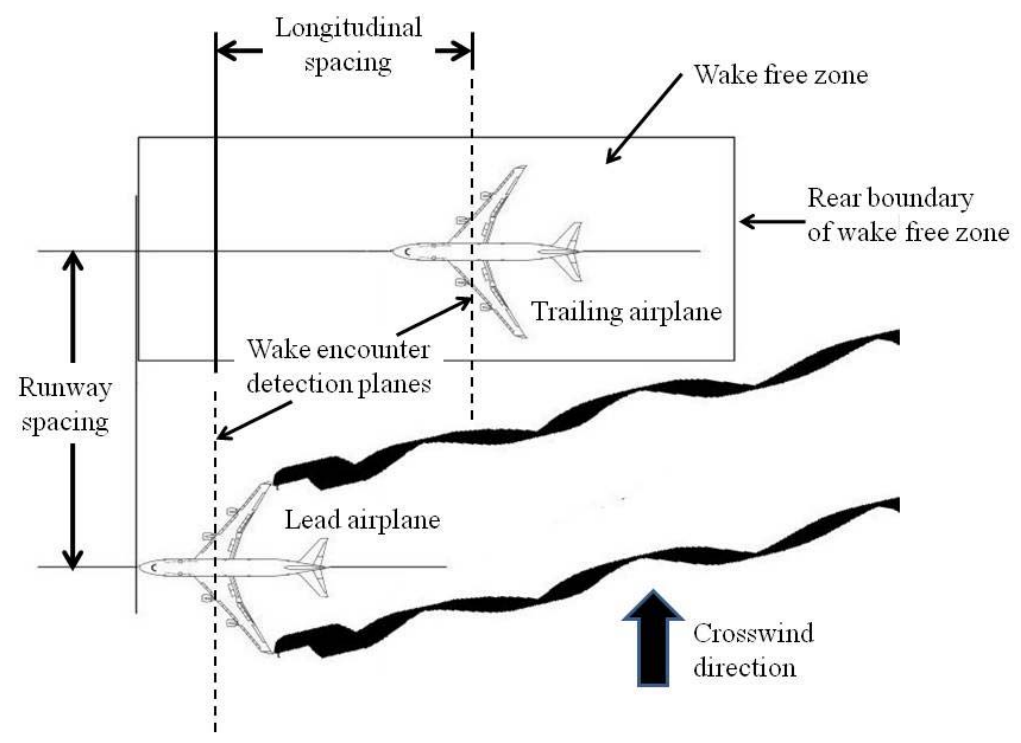

Figure 1. Paired approach "safe" or "wake free" zone

\section{Procedure}

The procedure used for this experiment involved two aircraft simultaneously performing instrument landing system (ILS) approaches and landings from the final approach fix (FAF) to touch down at a pair of CSPRs. The runway thresholds were not staggered. The aircraft weight class was "heavy." The runway separation, crosswind strength, and aircraft final approach speed were varied. Although one aircraft may be ahead of the other aircraft during the approach, the approach procedure was considered "simultaneous" because there was no in trail separation requirement due to wake turbulence as in current day operations. In this experiment, no consideration was made for a missed approach because it was considered to be outside the scope of the current study. 
Each run of the Monte Carlo simulation was initiated with two heavy aircraft positioned side-by-side on threedegree glide slopes at the final approach fixes of two closely spaced parallel runways. The lead aircraft was "released" from the FAF to proceed down the glide slope until reaching a specified distance between it and the following airplane. At that time, the following airplane started down the glide slope. By starting the run in this manner, the vortices of both the lead airplane and the trailing airplane were generated and properly modeled by the simulation software.

The initial conditions included combinations of (1) distance between runway centerlines (lateral distance between airplanes), (2) longitudinal spacing between airplanes, and (3) crosswind speed. Additionally, the nominal speed of the trailing airplane was either the same as the lead, $20 \mathrm{kt}$ faster than the lead, or $20 \mathrm{kt}$ slower than the lead during its transition from the FAF to the runway threshold. After passing the FAF, the lead airplane maintained a speed of $180 \mathrm{kt}$ until slowing for touchdown. Although the speed profiles used for this experiment were somewhat higher than what would normally be seen in today's airspace, it was felt that these speeds would help to more clearly see any differences in the rate of wake encounters due to different final approach speeds between the paired aircraft.

Thus, the four independent variables for this study were:

- Distance between runway centerlines, ft: 500, 750, 1000, 1250, 1500

- Initial longitudinal spacing between airplanes, ft: 0, 600, 1200, 2400

- Crosswind speed, kt: 0, 7.5, 15 with trailing airplane downwind of leading airplane at initiation of approach

- FAS difference of trailing versus lead airplane, kt: $-20,0,+20$.

The actual flight path of each airplane along its ILS approach to the runway incorporated statistical variation of navigation performance modeled with a normal distribution. In this simulation task the primary source of randomness was flight technical error. This error was manifested as initial off-sets from the three-degree glide slope at the final approach fix. The final approach fix was five nautical miles along the ground from the runway threshold. These off-sets were cross track error and vertical error. Initial indicated airspeed at the FAF was also chosen to be a uniform random variable between the limits of 175 and 185 knots. Cross track and vertical errors were zero.

Because wake vortex strength and persistence increase with aircraft weight, the airplane type used for the lead and trailing aircraft in this study was in the "heavy" wake turbulence category. Because ambient turbulence reduces the time for wakes to decay, a low level of ambient atmospheric turbulence was chosen for this study. With regard to crosswinds, a parallel approach procedure would likely position the trailing airplane such that the crosswind moves the wake of the leading airplane away from the trailing airplane. However, for this study, the more adverse case of the crosswind transporting the wake towards the trailing airplane was used. Each of these choices (aircraft weight, ambient turbulence level, and crosswind direction) were intended to add conservatism to the results of the study.

\section{Experiment}

\section{A. The Monte Carlo Simulation}

There are two primary components in the simulation: the aircraft flight from the final approach fix to touch down and the wake vortex dynamics. Details of these two parts are presented. Also, the simulation parameters chosen to be random variables and the method of determining a vortex encounter are discussed.

1) Monte Carlo Simulation Software

Monte Carlo simulations were conducted using the Wake Vortex Simulation and Analysis Tool (WVSAT ${ }^{\mathrm{TM}}$ ) developed by $(\mathrm{ATSI})^{5}$ and adapted for NASA's use. WVSAT ${ }^{\mathrm{TM}}$ consists of a group of computer tools that interact with each other and provide capabilities for (1) simulation, (2) visualization, and (3) analysis. Simulations utilize the Federal Aviation Administration's Aviation System Standard database and procedure templates. A wide variety of pseudo-random variables can be produced by $\mathrm{WVSAT}^{\mathrm{TM}}$, and the simulation's execution speed may be varied from $1 / 4$ to 50 times real time.

WVSAT $^{\mathrm{TM}}$ visualization capabilities enable the three-dimensional (3D) perspective display of wake vortices generated by aircraft and the analysis of wake vortex encounters with simulated aircraft. WVSAT ${ }^{\mathrm{TM}}$ provides $3 \mathrm{D}$ depiction of complex multi-aircraft operational scenarios, especially in the terminal area, including terrain, airports, runways and aircraft wake vortices. World Geodetic System calculations are employed to realistically and accurately render 3D images of aircraft, flight tracks, airports, runways, and other objects of interest to better understand the dynamics of a given operational situation.

WVSAT $^{\mathrm{TM}}$ predicts the wake vortex characteristics of a given airplane using its physical data, flight parameters, and environmental conditions. The wakes are modeled using NASA's AVOSS Prediction Algorithm 
(APA) version $3.2^{6}$ embedded in WVSAT ${ }^{\mathrm{TM}}$. APA 3.2 is a deterministic, fast-time wake vortex model and calculates the discrete vortex trajectories and circulation time histories. Vortex decay is formulated for two regions: out of ground effect (OGE - approximately greater than one wingspan of the generating aircraft) and in ground effect (IGE - approximately less than one wingspan).

The wake model uses inputs representing the generating aircraft (such as weight, airspeed, wingspan, lateral position, and altitude) and atmospheric environment (such as ambient winds, turbulence, and temperature lapse rate). Fast-time models do not provide the wake-vortex flow field details found in Large Eddy Simulation (LES) models such as can be provided with the Terminal Area Simulation System (TASS) ${ }^{7,8}$. Fast-time models can not directly predict the meandering vortex paths resulting from atmospheric turbulence, sinusoidal displacements or vortex breakup into vortex rings resulting from Crow instability'. The APA model predicts wake vortex trajectories and circulations within a plane perpendicular to the path of the generating aircraft. The initial wake is represented as two vortices whose initial strength and position are dependent upon input conditions. If the wake is out of ground effect, the APA model utilizes a decay and transport model developed by Sarpkaya ${ }^{10}$. For in ground effect, APA utilizes image vortices to represent the effect of an impenetrable ground, and the introduction of secondary vortices that cause wake vortex rebound. In APA version 3.2, IGE decay is computed with a formula derived from a TASS LES study ${ }^{11}$.

\section{2) Vortex Encounter Method}

As shown in Fig. 2, WVSAT ${ }^{\mathrm{TM}}$ utilizes an area of interest (AOI) to determine where an encounter occurs. For this study, the AOI was defined as an ellipse with semimajor axis equal to $1 \frac{1}{2}$ wing spans, centered at the center of gravity of each airplane, perpendicular to the longitudinal axis of the airplane, and extending along the wing span. In this study a wake was generated at one-second intervals and a wake was detected at 0.2 second timed intervals. A wake encounter was defined as the closest point from the wake to the aircraft center of gravity once the wake penetrated the AOI. The extent of the wake was defined by a minimum circulation strength of $80 \mathrm{~m}^{2} / \mathrm{s}^{3}$.

\section{B. Experiment Design}

The experiment design was a $4 \times 3 \times 3 \times 5$ factorial with 2500 replications

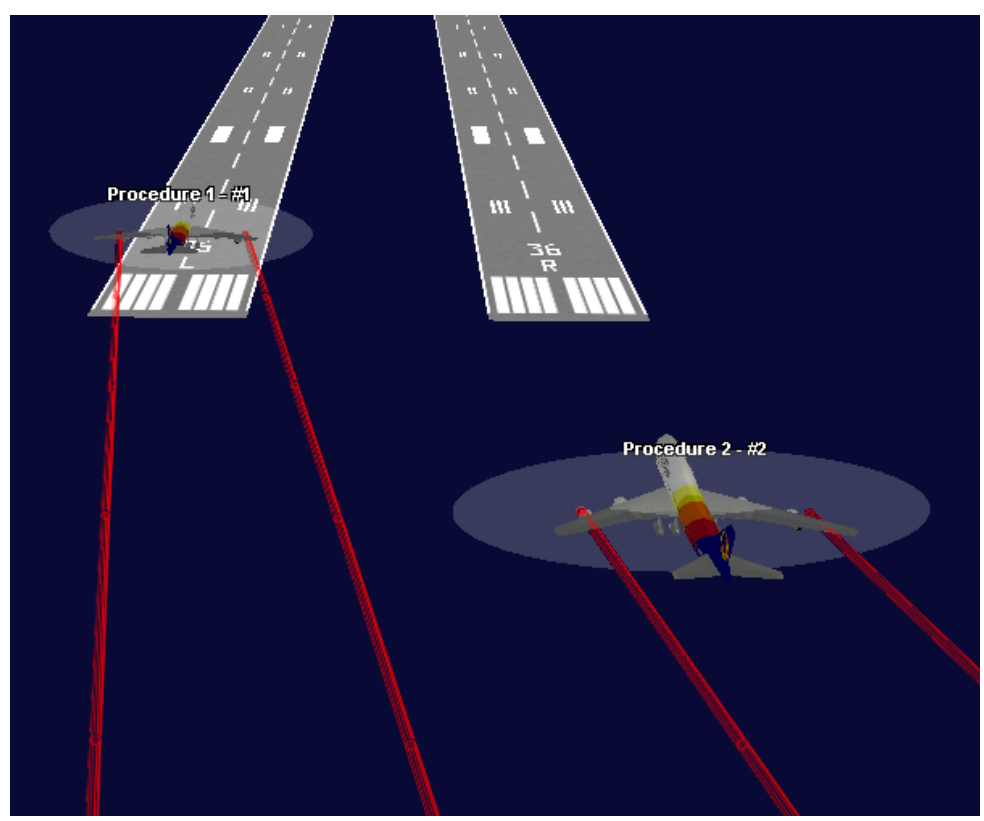

Figure 2. Illustration of parallel approaches showing wakes and wake detection area of interest ellipses per cell. The factors are aircraft longitudinal spacing at the final approach fix $(0,600,1200,2400 \mathrm{ft})$, crosswind speed $(0,7.5,15 \mathrm{kt})$, aircraft final approach speed difference $(-20,0,+20 \mathrm{kt})$, and runway centerline separation $(500,750,1000,1250,1500 \mathrm{ft})$. The flight procedural parameters, atmospheric conditions, and wake vortex parameters used in the simulation are presented in Table 1.

Table 1. Simulation Parameters 


\begin{tabular}{|c|c|}
\hline & Wingspan $211.8 \mathrm{ft}$ \\
\hline Glide Slope Angle & Normal- $3^{\circ}$, Bounds- $2.8-3.2^{\circ}$ \\
\hline Threshold Crossing Height & Normal $-(50,2.8) \mathrm{ft}$, Bounds $45-55 \mathrm{ft}$ \\
\hline Start Distance & $5.0 \mathrm{~nm}$, leader constant, trailer constant \\
\hline Initial Air Speed & $\begin{array}{l}\text { Uniform }-180 \mathrm{kt} \text {, bounds } 175-185 \\
\mathrm{kt} \text {, leader constant, trailer varied }\end{array}$ \\
\hline Flare Altitude & Normal - $(45,1) \mathrm{ft}$, Bounds $40-50 \mathrm{ft}$ \\
\hline Touch Down Point Distance Beyond Threshold & Normal $-1800 \mathrm{ft}$, Bounds $1750-1850 \mathrm{ft}$ \\
\hline Air Speed at Touch-down & $150 \mathrm{kt}$ \\
\hline Crosswind Speed & $0,7.5,15 \mathrm{kt}$ constant from surface to $5000 \mathrm{ft}$ \\
\hline Air Temperature & $15 \mathrm{C}$ at surface; $5 \mathrm{C}$ at $5000 \mathrm{ft}$ \\
\hline EDR & $\begin{array}{c}0.0001 \mathrm{~m}^{2} / \mathrm{s}^{3} \text { constant from surface } \\
\text { to } 5000 \mathrm{ft}\end{array}$ \\
\hline Generating Interval & $1 \mathrm{~s}$ \\
\hline $\begin{array}{l}\text { Detection Area of Interest } \\
\text { (Ellipse) }\end{array}$ & $\begin{array}{l}\text { Major (lateral) Axis } 318 \mathrm{ft} \\
\text { Minor (vertical) Axis } 106 \mathrm{ft}\end{array}$ \\
\hline
\end{tabular}

1) Number of Samples

For a maximum relative error per cell of $20 \%$ with a $90 \%$ confidence interval and 0.63 s fhequemoz of moounter $(f) \leq 0.97,2330$ samples are needed. For this study, 2500 samples per cell were used.

2) Statistics/Response/Dependent Variables

Six statistics were computed for each wake encounter: the relative frequency $(f)$ of a vortex encounter, the distance $(D)$ from the far end of the runway when the vortex encounter occurred, the wake altitude $H$ (height at which the vortex encounter occurred), and relative lateral (Rlt), longitudinal (Rlo) and vertical (Rvt) positions between the two aircraft at the vortex encounter. Of these six measures, $f$ and Rlo were the most important because they were used as the primary measure to determine the rear boundary of the wake free zone. $D, H$, Rlt and $R v t$ are physical measures of the vortex encounter.

3) Hypotheses

$\mathrm{H}_{0}$ (Null hypothesis): each dependent variable is constant as the factors are varied.

$\mathrm{H}_{1}$ (Alternate hypothesis): each dependent variable is not constant as the factors are varied.

More specifically, more encounters are expected when the runways are closer together or the crosswinds are higher or the paired approach speed differences are greater.

4) Statistical Inference

$f$ is a relative frequency estimate of a probability and $f$ will be presented with its $99 \%$ confidence interval. Non intersecting confidence intervals were viewed as indicating statistically significant differences. MATLAB Statistics Toolbox $7^{14}$, Microsoft Excel $2007^{15}$ and R version 2.7.2. ${ }^{16}$ were used to perform the statistical analyses and to generate the graphs.

\section{Results and Discussion}

In this section general statistics, main effects, interaction effects for relative frequency and the relevance of the experiment factors to operations at CSPR's will be discussed.

\section{A. General Statistics}

In this study, the $4 \times 3 \times 3 \times 5$ factorial design resulted in 180 discrete cases, each being run 2500 times for a total of 450,000 samples. Overall, 57,673 vortex encounters resulted. Of these, 2085 were multiple encounters (more than one encounter per sample). The empirical probability, or relative frequency of an encounter was 0.1282 with a $99 \%$ confidence interval of $[0.1269,0.1295]$. Similarly, the relative frequency of a multiple encounter was 0.004633 with a $99 \%$ confidence interval of $[0.004379,0.004902]$. These numbers imply that, with respect to this experiment, a vortex encounter was not a rare event. And given that there was an encounter, the probability that the sample contains a multiple encounter was 0.03615 with a $99 \%$ confidence interval of [0.03420, 0.03821].

\section{B. Main Effects for Relative Frequency}


The primary dependent variable is relative frequency of vortex encounter. Figure 3 contains four graphs of relative frequency across the four independent variables (factors): speed difference, runway separation, aircraft longitudinal spacing, and crosswind. Within each graph, the confidence intervals do not overlap, suggesting that there are statistically significant variations within each factor. The factor with the largest influence (based on the range of relative frequency) is runway separation. The next most influential factor is speed difference. They are followed by crosswind speed and, finally, aircraft longitudinal spacing. It is not surprising that runway separation would have a major influence on wake encounters. Intuitively one would expect that smaller separation distances would lead to more encounters. These data support one's intuitive thoughts. In the case of speed difference the ability to maintain the same aircraft speed relative to that of the lead aircraft has a major influence on whether or not there is a vortex encounter. Speed differences on final approach translate into unintended aircraft spacing which lead to wake encounters. It should be noted that for runway separations of 1250 and $1500 \mathrm{ft}$ and for a speed difference of $20 \mathrm{kt}$ the relative frequencies of wake encounters were very low: respectively, $0.001222,0.0000333$ and 0.000647 . The importance of the factors speed difference and runway separation is further emphasized by their large relative
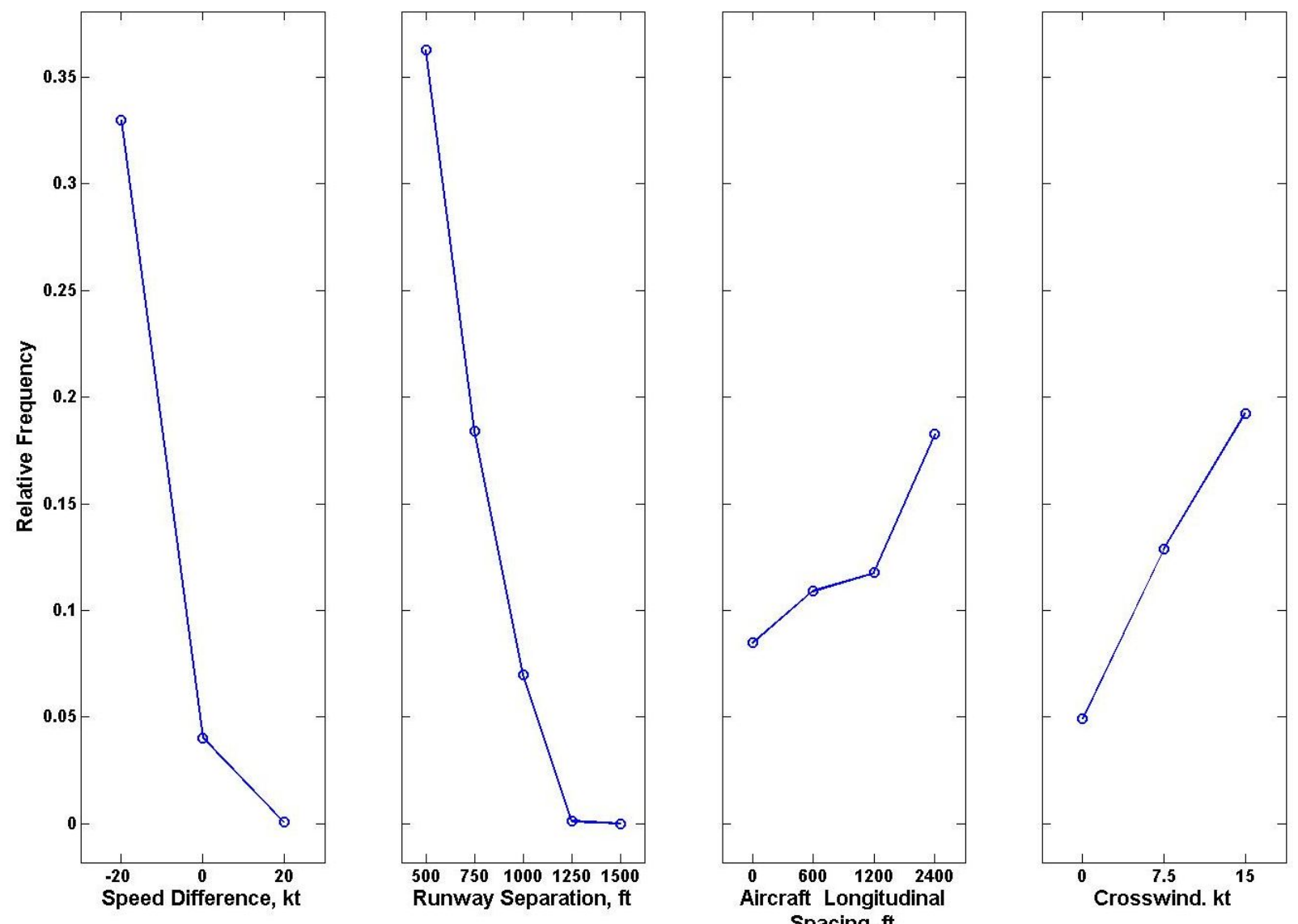

Figure 3. Relative Frequency across the four factors

frequencies at a speed difference of $-20 \mathrm{kt}$ and a runway separation of $500 \mathrm{ft}$ ( 0.329707 and 0.362622 respectively). Under the conditions of a speed difference of $-20 \mathrm{kt}$ (that is, the trailing aircraft was falling behind the leader) and/or a runway separation of 500 feet there were wake vortex encounters at least $1 / 3$ of the time.

\section{Interaction Effects for Relative Frequency}

Figure 4 is an "interactionplot" ${ }^{14}$ of relative frequency across the four factors, and provides an excellent means of displaying the interaction effect between pairs of factors. A visual inspection of the plots suggests that the interaction effect is strong for all pair-wise combinations of factors. Pearson's $\chi^{2}$ (Chi-squared) tests of the interaction effects using contingency tables support the visual observations. Two of the six possible contingency tables (Tables 2 and 3 ) are shown. The P-value for each test is less than 0.0001. Small P-values provide evidence for rejecting the null hypotheses that there were no interaction effects. Table 2 contains the counts for the weakest 
interaction (ranked by $\chi^{2} /$ degrees of freedom) of aircraft spacing by runway separations. Table 3 has the counts for the strongest interaction: runway separation by crosswind. The "interactionplot" and the contingency tables support the intuitive thought that combinations of factors (runway separation and crosswind for example) increase the probability of an encounter as the factor values move from weaker values (runway separation $=1500$ and crosswind $=0$ ) to stronger values (runway separation $=500$ and crosswind $=15$ ). This phenomenon occurs for all combinations of factors.

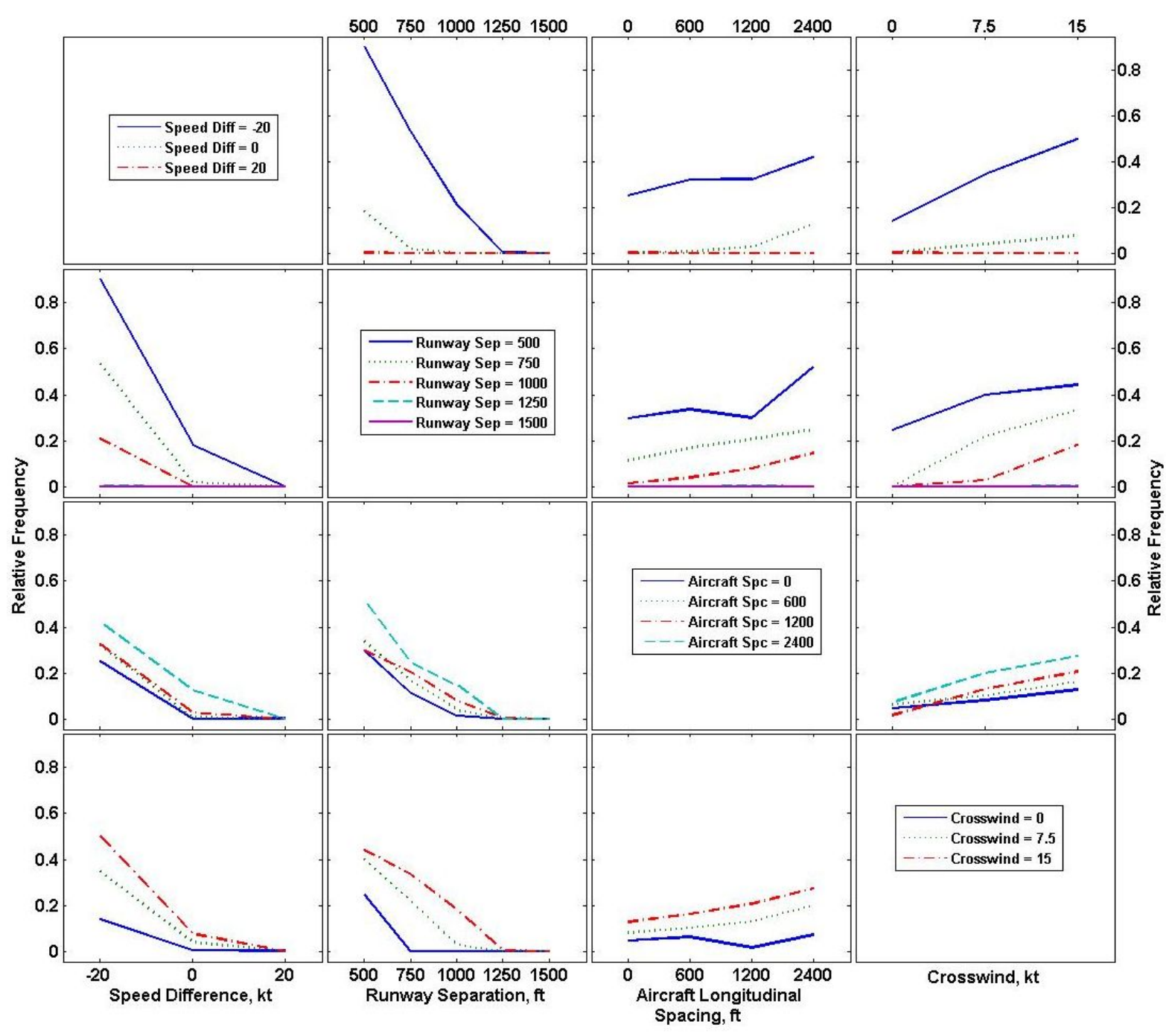

Figure 4. Interaction plot for relative frequency

Table 2. Number of Wake Encounters by Initial Aircraft Longitudinal Spacing and Runway Separation $\left(\chi^{2}=2143.767,12\right.$ degrees of freedom)

\begin{tabular}{|c|c|c|c|c|c|c|}
\hline \multirow{2}{*}{$\begin{array}{c}\text { Initial Aircraft } \\
\text { Longitudinal Spacing, } \mathrm{ft}\end{array}$} & \multicolumn{3}{|c|}{ Runway Separation, $\mathrm{ft}$} & \multirow[b]{2}{*}{1250} & \multirow[b]{2}{*}{1500} & \multirow[b]{2}{*}{ Grand Total } \\
\hline & 500 & 750 & 1000 & & & \\
\hline 0 & 6689 & 2558 & 293 & 0 & 0 & 9540 \\
\hline 600 & 7573 & 3789 & 913 & 0 & 0 & 12275 \\
\hline 1200 & 6720 & 4625 & 1775 & 110 & 0 & 13230 \\
\hline 2400 & 11654 & 5580 & 3305 & 0 & 3 & 20542 \\
\hline Grand Total & 32636 & 16552 & 6286 & 110 & 3 & 55587 \\
\hline
\end{tabular}


Table 3. Number of Wake Encounters by Runway Separation and Crosswind Speed $\left(\chi^{2}=8734.221,8\right.$ degrees of freedom)

\begin{tabular}{|c|r|r|r|r|}
\hline Runway & \multicolumn{3}{|c|}{ Crosswind Speed, kt } & \\
Separation, $\mathrm{ft}$ & 0 & 7.5 & 15 & Grand Total \\
\hline 500 & 7375 & 11964 & 13297 & 32636 \\
750 & 22 & 6543 & 9987 & 16552 \\
1000 & 0 & 810 & 5476 & 6286 \\
1250 & 0 & 0 & 110 & 110 \\
1500 & 0 & 0 & 3 & 3 \\
\hline Grand Total & 7397 & 19317 & 28873 & 55587 \\
\hline
\end{tabular}

\section{Safe Zone Analysis and Summary Statistics for the Dependent Variables}

Before an analysis of the safe zone a few comments about Figure 4 are in order. This figure presents the positions of all wake vortex encounters relative to the ground and the far end of the runway. In the experiment a $10,000 \mathrm{ft}$ runway was used. The majority of the encounters occur very close to the runway threshold or over the runway. Ground effects in the form of accelerated lateral motion of vortices, slowing of vertical descent and rising vortices are contributors to encounters. More comments will be made about the encounters over and near the runway in the following paragraphs.

After an examination of the data and information from Figure 4, the data were divided into three parts for safe zone analysis: 1) speed difference was $20 \mathrm{kt}$; 2) wake altitude was less than $225 \mathrm{ft}$ but not including a speed difference of $20 \mathrm{kt}$ and; 3) wake altitude was at least $225 \mathrm{ft}$.

When the speed difference was $20 \mathrm{kt}$ (i.e., trailing aircraft passed the lead aircraft), there were 97 encounters. Four of the encounters occurred when the runway separation was 500 $\mathrm{ft}$, aircraft spacing was $600 \mathrm{ft}$ and crosswind was $0 \mathrm{kt}$. The remaining 93 encounters occurred when the runway separation was 500 $\mathrm{ft}$, aircraft spacing was $0 \mathrm{ft}$ and crosswind was 0 kt. Table 4 contains the summary statistics for the dependent variables for the factor: speed difference equals $20 \mathrm{kt}$. These encounters are from the situation where the trailing aircraft has become the leader and the old leader, now a trailing aircraft, has a wake vortex encounter. Important facts to note from Table 4 are the mean wake encounter altitude

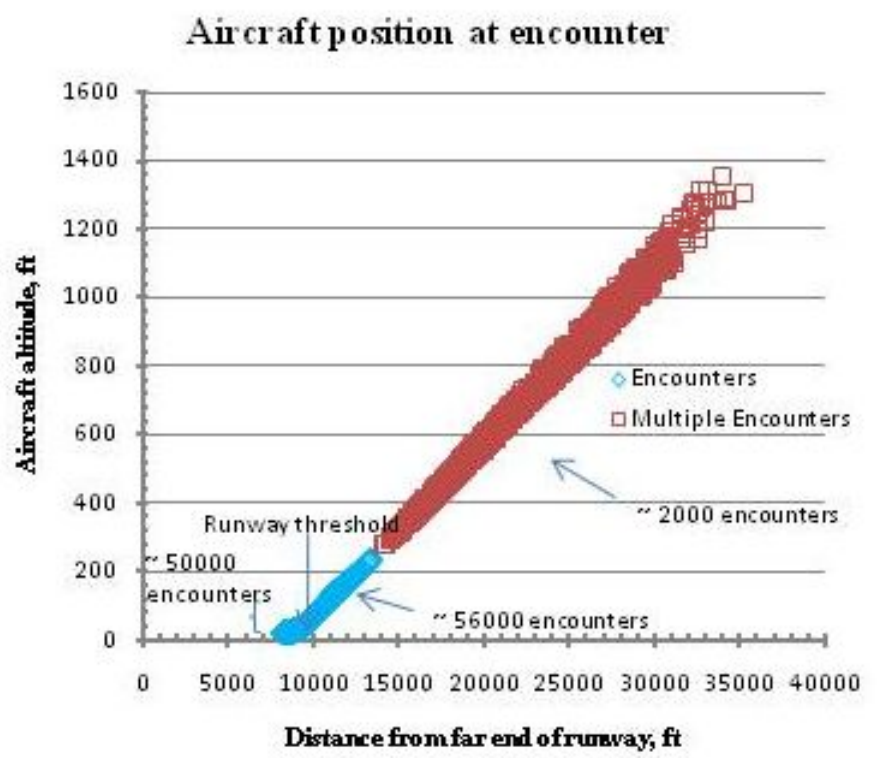

Figure 4. Aircraft position at time of wake encounter is $23.62 \mathrm{ft}$ and the distance from the far end of the runway is $8365.297 \mathrm{ft}$. Ground effects influence all of the encounters. These encounters occurred just prior to touchdown for the trailing aircraft. The relative frequency of encounter for these samples is very low (0.00323). Figure 5 shows the 97 encounters. The data determines the rear boundary of the safe zone. Therefore, the safe zone is the region between the data and the lateral distance axis at the $500 \mathrm{ft}$ point. This would be the place that is free of wake encounters for the conditions of a speed difference of $20 \mathrm{kt}$, 
a runway separation of $500 \mathrm{ft}$, an aircraft spacing of 0 or $600 \mathrm{ft}$, and $0 \mathrm{kt}$ crosswind. One way of specifying the safe zone is by using the minimum longitudinal position. The follower is in the safe zone if its' longitudinal position is less than $3520 \mathrm{ft}$, the minimum value in Table 4, when runway separation is $500 \mathrm{ft}$ and speed difference is $20 \mathrm{kt}$. Otherwise, when the speed difference is $20 \mathrm{kt}$; the safe zone is "unrestricted", that is, there are no rear boundaries to the safe zone for runway separations greater than $500 \mathrm{ft}$ and the speed difference is $20 \mathrm{kt}$.

Table 4. Summary Statistics when Speed Difference Equals 20 kt

\begin{tabular}{|c|l|l|l|l|l|}
\hline & $\begin{array}{c}H, \text { Wake } \\
\text { Altitude, } \\
\mathrm{ft}\end{array}$ & $\begin{array}{c}R / t, \\
\text { Lateral } \\
\text { Position, } \\
\mathrm{ft}\end{array}$ & $\begin{array}{c}\text { Rlo, } \\
\text { Longitudinal } \\
\text { Position, } \mathrm{ft}\end{array}$ & $\begin{array}{c}\text { Rvt, Vertical } \\
\text { Position, ft }\end{array}$ & $\begin{array}{l}\text { D, Distance } \\
\text { from Far End } \\
\text { of Runway, ft }\end{array}$ \\
\hline Minimum & 22.29 & 499.3 & 3520 & 21.21 & 8248 \\
\hline $\begin{array}{c}1^{\text {st }} \\
\text { Quartile }\end{array}$ & 22.87 & 499.3 & 3737 & 21.31 & 8248 \\
\hline Median & 23.39 & 499.3 & 3846.181 & 21.467 & 8359.722 \\
\hline Mean & 23.62 & 499.3 & 3838.790 & 21.575 & 8365.297 \\
\hline $\begin{array}{c}\text { Standard } \\
\text { Deviation }\end{array}$ & 0.897 & $6.841 \mathrm{e}-05$ & 146.8998 & 0.342 & 69.839 \\
\hline $\begin{array}{c}3^{\text {rd }} \\
\text { Quartile }\end{array}$ & 24.17 & 499.3 & 3937 & 21.71 & 8416 \\
\hline Maximum & 26.07 & 499.3 & 4160 & 22.64 & 8523 \\
\hline
\end{tabular}

When the aircraft altitude was less than $225 \mathrm{ft}$ there were 55,592 encounters. This is the majority of the data. Table 5 contains summary statistics for the dependent variables. Figure 6 shows the 55,592 encounters. The safe zone is the region between the data and origin. In this case the rear boundary sweeps across all runway separations and there are no unrestricted conditions for the safe zone. Figure 7 provides a picture of the safe zone for the 55,592 encounters. Figure 7 is a projection of the data in Figure 6 onto the lateral distancelongitudinal distance plane. The safe zone is the shaded area in Figure 7. As the runway separation increases the safe zone increases and the relative frequency of an encounter outside the safe zone

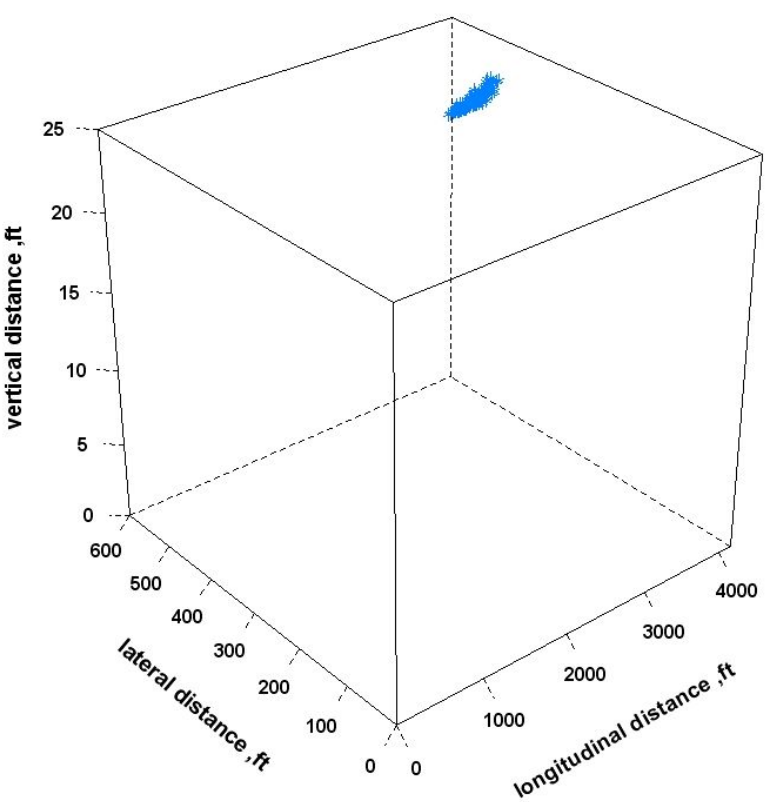

Figure 5. Safe Zone for Speed Difference of 20 kt and Runway Separation of $500 \mathrm{ft}$ decreases. For a runway separation of $500 \mathrm{ft}$ there were 32611 encounters. The relative frequency is 0.36234 . This means, given a runway separation of $500 \mathrm{ft}$ and an aircraft altitude less than $225 \mathrm{ft}$ there will be a wake encounter between $35.8 \%$ and $36.6 \%$ of the time with a $99 \%$ confidence interval. Similar reasoning applies to the other four runway separations. For a runway separation of $750 \mathrm{ft}$ there were 16571 encounters. The relative frequency is 0.18412 with a $99 \%$ confidence interval of $[0.1808,0.1875]$. For a runway separation of 1000 feet there were 6297 encounters. The relative frequency is 
0.06997 with a $99 \%$ confidence interval of [0.06781, 0.07219]. For a runway separation of $1250 \mathrm{ft}$ there were 110 encounters. The relative frequency is 0.00122 with a $99 \%$ confidence interval of [0.000956, 0.001562]. Finally, for a runway separation of $1500 \mathrm{ft}$ there were 3 encounters. The relative frequency is $3.333 \mathrm{e}-05$ with a $99 \%$ confidence interval of [8.4e-06, 0.000132].

When the wake altitude was at least $225 \mathrm{ft}$ there were 1984 encounters. Table 6 contains summary statistics for the dependent variables. Figure 8 shows the 1984 encounters. These data represent wake encounters away from the runway. The wake altitude varied between 225.8 and $1307.2 \mathrm{ft}$, while the distance from the runway threshold (distance from the runway far end minus 10,000 ft) varied from 4137 to $25,205 \mathrm{ft}$. Two properties of these data are important: the runway separation was $500 \mathrm{ft}$ and the crosswind was $15 \mathrm{kt}$. Again, the safe zone is determined by the region between the data and the origin. The follower is in the safe zone if its longitudinal position is less than 3159 $\mathrm{ft}$, the minimum value in Table 6 , when runway separation is $500 \mathrm{ft}$. For other runway separations, the safe zone is "unrestricted". The relative frequency of these 1984 samples is 0.02044 with a $99 \%$ confidence interval of [0.02082, 0.02334]. These are low values.

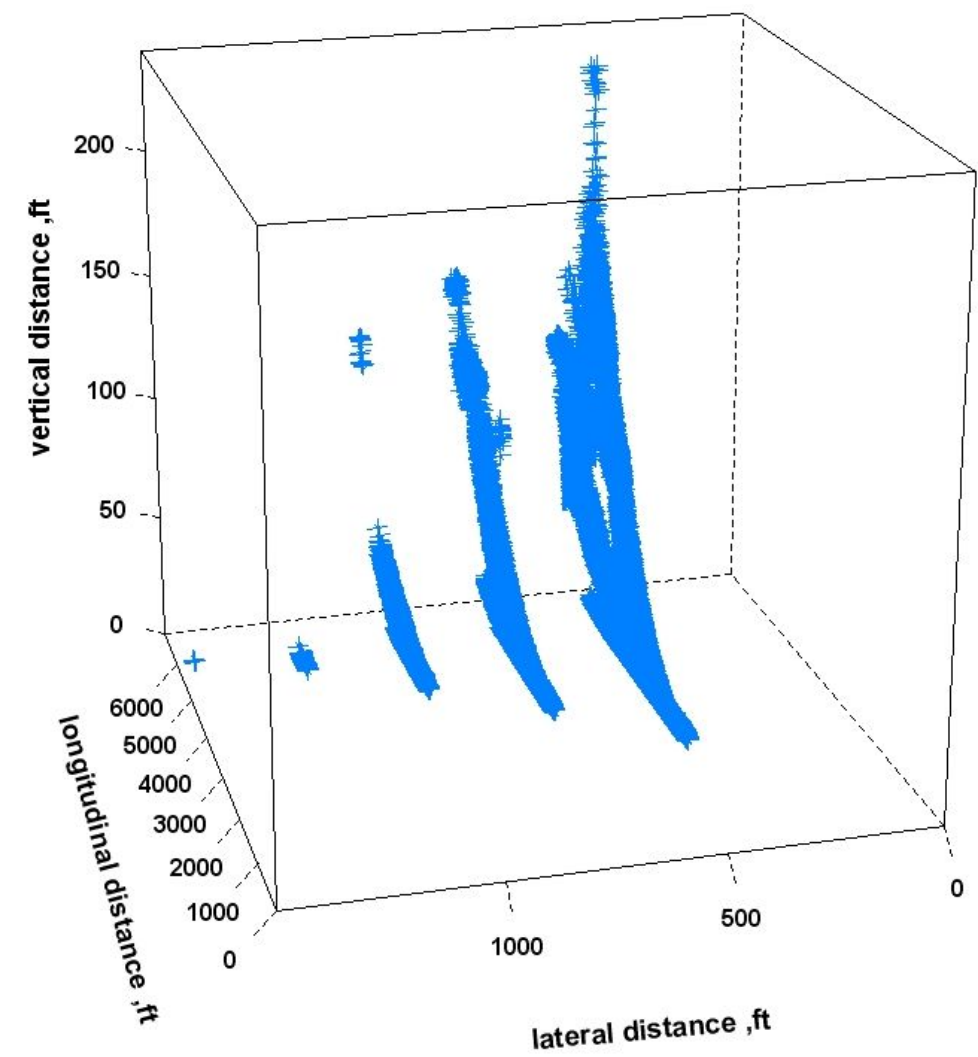

Figure 6. Data when Wake Altitude was Less Than $225 \mathrm{ft}$

Table 5. Summary Statistics when Wake Altitude was Less Than $225 \mathrm{ft}$ 


\begin{tabular}{|c|c|c|c|c|c|}
\hline & $\begin{array}{l}\mathrm{H}, \quad \text { Wake } \\
\text { Altitude, } \mathrm{ft}\end{array}$ & $\begin{array}{l}R / t \text {, Lateral } \\
\text { Position, } \mathrm{ft}\end{array}$ & $\begin{array}{l}\text { Rlo, } \\
\text { Longitudinal } \\
\text { Position, } \mathrm{ft}\end{array}$ & $\begin{array}{l}\text { Rvt, Vertical } \\
\text { Position, } \mathrm{ft}\end{array}$ & $\begin{array}{l}D \text {, Distance } \\
\text { from Far } \\
\text { End of } \\
\text { Runway, } \mathrm{ft}\end{array}$ \\
\hline Minimum & 18.22 & 499.3 & 1382 & 21.20 & 8212 \\
\hline $1^{\text {st }}$ Quartile & 24.42 & 499.3 & 3250 & 21.87 & 8436 \\
\hline Median & 28.45 & 499.3 & 3862 & 24.39 & 8679 \\
\hline Mean & 42.10 & 631.6 & 3877 & 41.16 & 9063 \\
\hline $\begin{array}{l}\text { Standard } \\
\text { Deviation }\end{array}$ & 26.497 & 174.299 & 964.875 & 32.506 & 861.676 \\
\hline $3^{\text {rd }}$ Quartile & 50.16 & 748.4 & 4514 & 43.56 & 9422 \\
\hline Maximum & 186.28 & 1497.8 & 6909 & 238.51 & 13421 \\
\hline
\end{tabular}

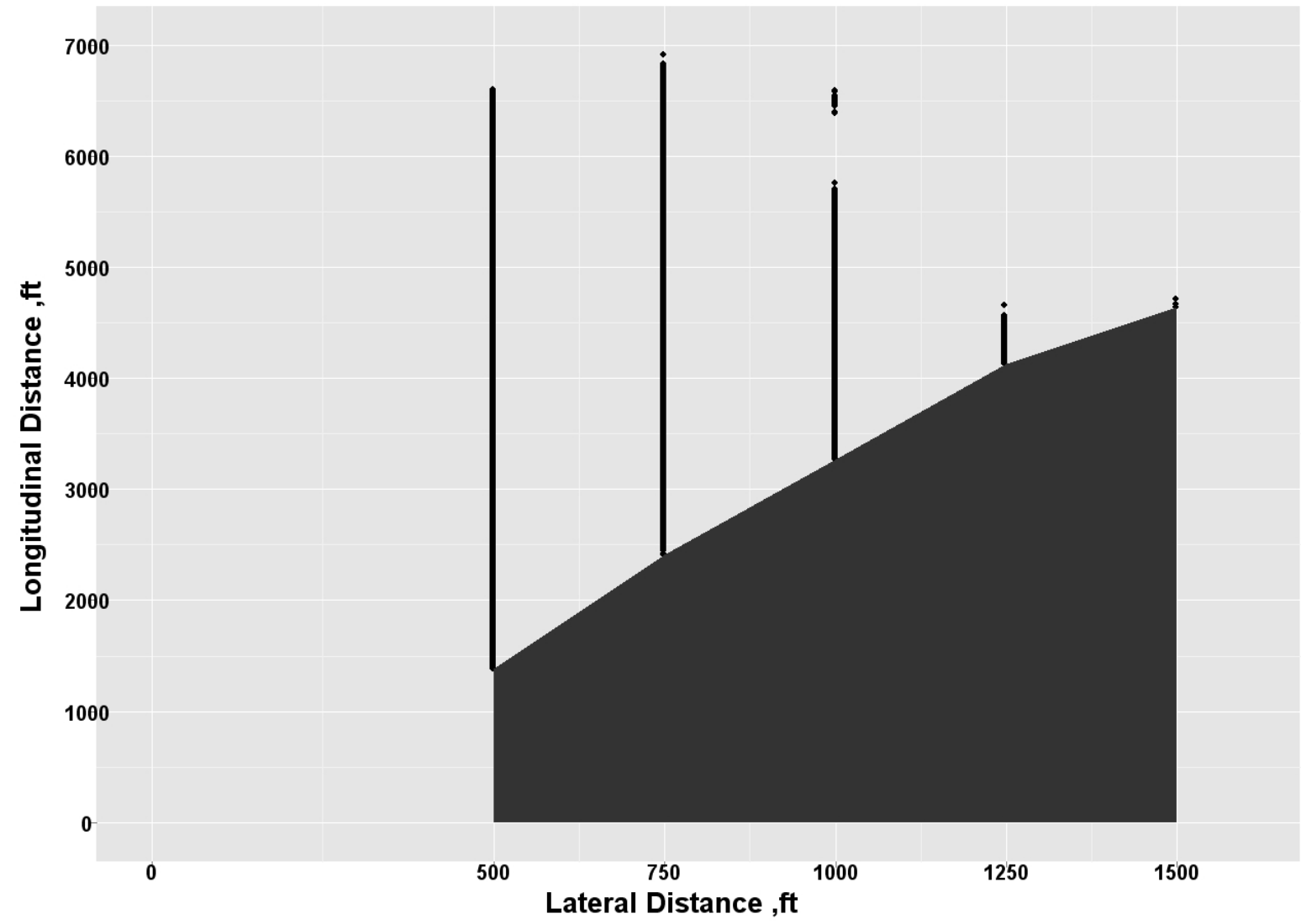

Figure 7. Safe Zone (shaded area) for Wake Altitude Less Than $225 \mathrm{ft}$ 
Table 6. Summary Statistics for Samples where Wake Altitude is At Least 225 ft

\begin{tabular}{|c|c|c|l|l|c|}
\hline & $\begin{array}{l}H, \quad \begin{array}{l}\text { Wake } \\
\text { Altitude, } \mathrm{ft}\end{array} \\
\text { Lateral } \\
\text { Position, } \\
\mathrm{ft}\end{array}$ & $\begin{array}{l}\text { Rlo, } \\
\text { Longitudinal } \\
\text { Position, } \mathrm{ft}\end{array}$ & $\begin{array}{l}\text { Rvt, Vertical } \\
\text { Position, } \mathrm{ft}\end{array}$ & $\begin{array}{l}\text { D, Distance } \\
\text { from Far End } \\
\text { of Runway, } \mathrm{ft}\end{array}$ \\
\hline Minimum & 225.8 & 499.3 & 3159 & 276.6 & 14137 \\
\hline $\begin{array}{c}1^{\text {st }} \\
\text { Quartile }\end{array}$ & 387.8 & 499.3 & 4234 & 433.5 & 17189 \\
\hline Median & 588.3 & 499.3 & 4671 & 630.0 & 21029 \\
\hline Mean & 625.1 & 499.3 & 4530 & 664.2 & 21744 \\
\hline $\begin{array}{c}\text { Standard } \\
\text { Deviation }\end{array}$ & $2.557848 \mathrm{e}+02$ & $\begin{array}{c}1.0895 \mathrm{e}- \\
04\end{array}$ & $4.71289 \mathrm{e}+02$ & $2.51418 \mathrm{e}+02$ & $4.896343 \mathrm{e}+03$ \\
\hline $\begin{array}{c}3^{\text {rd }} \\
\text { Quartile }\end{array}$ & 854.9 & 499.3 & 4899 & 882.3 & 26098 \\
\hline Maximum & 1307.2 & 499.3 & 5467 & 1355.4 & 35205 \\
\hline
\end{tabular}

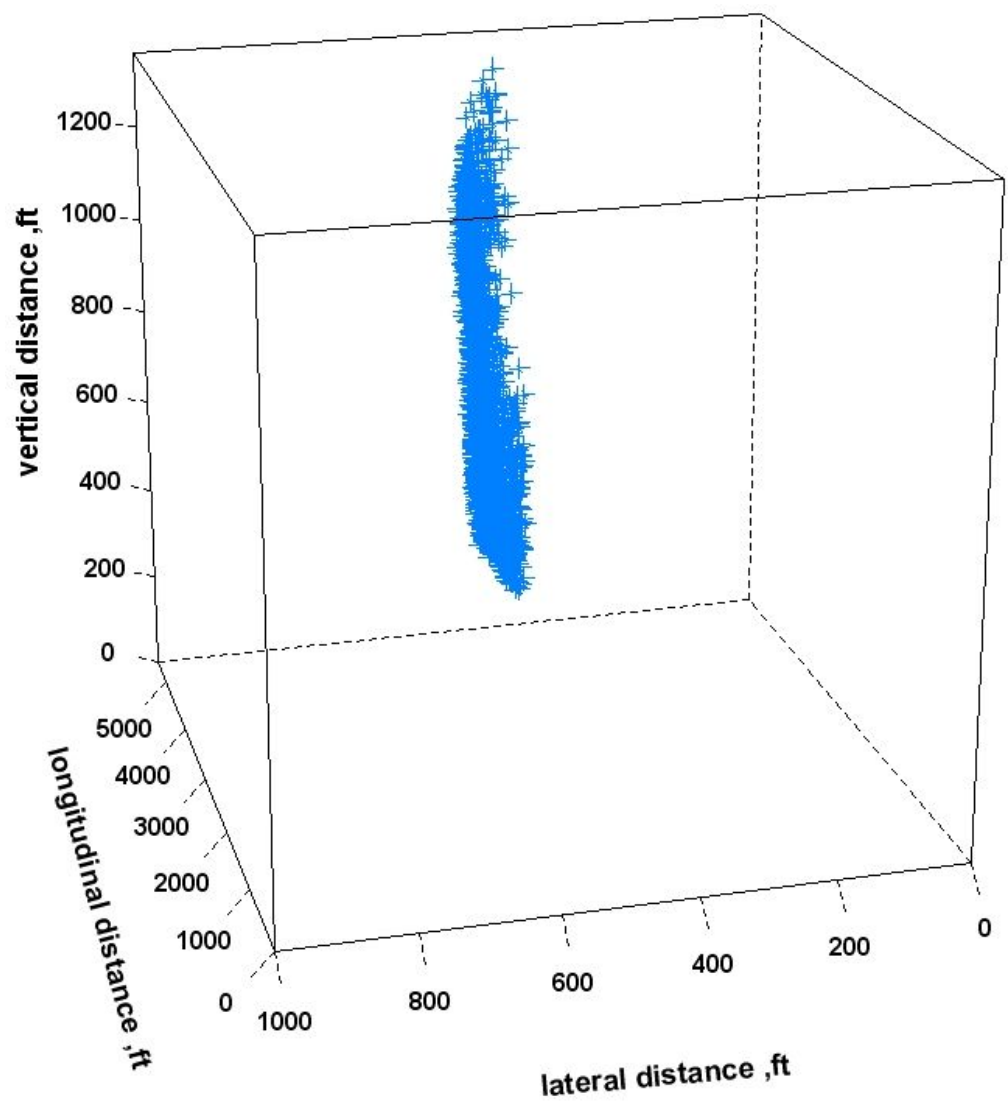

Figure 8. Data when Wake Altitude is At Least $225 \mathrm{ft}$ 


\section{Summary and Conclusions}

All factors (speed difference, runway separation, aircraft spacing and crosswind) have a strong influence on the probability of a wake vortex encounter. Combinations of factors increase the probability of an encounter. The strongest combination is runway separation and crosswind. At closer runway separations and higher crosswind speeds more wake encounters occurred. Most of the encounters occurred just prior to landing by the following aircraft. At these very low altitudes, ground effect would be the major influence on the vortex. Accelerated lateral travel, slowing of vertical descent and an upward movement of the wake would lead to more encounters. This experiment suggests that special attention should be given to the landing phase of aircraft operations when CSPR's are used. Special attention should also be given to runway separations of 1250 and $1500 \mathrm{ft}$. The probability of encounters at runway separations of $1250 \mathrm{ft}$ and $1500 \mathrm{ft}$ are quite low, they are, respectively: 0.0012 and 0.000033 . These encounters only occur when the crosswind is high ( $15 \mathrm{kt})$ and the speed difference is $-20 \mathrm{kt}$.

The main objective of the experiment was to determine the rear boundary of a "paired approach safe zone" that will be defined by wake vortex characteristics, geometric parameters, and aircraft performance parameters by performing a Monte Carlo experiment using the Wake Vortex Simulation and Analysis Tool (WVSAT). This was successfully done. The safe zone is given in terms of the longitudinal distance between leader and follower. In order to determine the safe zone the data was divided into three groups: (1) speed difference was $20 \mathrm{kt}$, (2) wake altitude was less than $225 \mathrm{ft}$ but not including a speed difference of $20 \mathrm{kt}$ and (3) wake altitude was at least 225 feet.

In group (1) the rear boundary is at $3250 \mathrm{ft}$ behind the lead aircraft on $500 \mathrm{ft}$ runway, zero crosswind, $20 \mathrm{kt}$ speed difference and zero or $600 \mathrm{ft}$ aircraft spacing. When the aircraft are closer than $3250 \mathrm{ft}$, then the follower is in the safe zone where no wake vortex encounters occur. For other runway separations under all experiment factors the safe zone is "unrestricted", that is, there are no rear boundaries. The relative frequency (probability) of group (1) is low, 0.00323 , and all of the encounters occur over the runway at low altitudes, $26.07 \mathrm{ft}$ or less.

For group (2) the rear boundaries were over all runway separations and there were no "unrestricted safe zones". The rear boundaries ranged from $1382 \mathrm{ft}$ for $500 \mathrm{ft}$ runway separation to $4640 \mathrm{ft}$ for $1500 \mathrm{ft}$ runway separation. The rear boundaries are specified by the minimum longitudinal distances. Table 7 lists all the boundaries for each runway separation and the relative frequencies of encounter. Most of the data falls into group (2) and the relative frequencies for runway separations of 500,750 and $1000 \mathrm{ft}$ are considered high. When the longitudinal distance is less than the safe zone boundary value there are no encounters. Group (2) data represents low altitude encounters near and over the runway. The median wake altitude is $28.45 \mathrm{ft}$ and the median distance from the far end of the runway at encounter is $9063 \mathrm{ft}$.

Table 7. Safe Zone Boundaries for Wake Altitude Less Than $225 \mathrm{ft}$

\begin{tabular}{|c|c|c|c|c|c|}
\hline \multicolumn{5}{|c|}{ Runway Separations } \\
\hline $\begin{array}{c}\text { Rear "Safe Zone" } \\
\text { Boundary }\end{array}$ & $1300 \mathrm{ft}$ & $750 \mathrm{ft}$ & $1000 \mathrm{ft}$ & $1250 \mathrm{ft}$ & $1500 \mathrm{ft}$ \\
\hline $\begin{array}{c}\text { Relative Frequency } \\
\text { of Encounter }\end{array}$ & 0.36234 & $2411 \mathrm{ft}$ & $3268 \mathrm{ft}$ & $4131 \mathrm{ft}$ & $4640 \mathrm{ft}$ \\
\hline
\end{tabular}

Group (3) data represent wake vortex encounters away from the runway. The median wake altitude is $588.3 \mathrm{ft}$ and the median distance from the far end of the runway is $21029 \mathrm{ft}$. All of these encounters occurred at a runway separation of $500 \mathrm{ft}$ with a crosswind of $15 \mathrm{kt}$. The safe zone rear boundary is at $3159 \mathrm{ft}$. When the longitudinal distance is smaller than 3159 then the follower aircraft is in the safe zone where there are no wake encounters. For conditions other than a $500 \mathrm{ft}$ runway separation with 15 knots crosswind the safe zone is "unrestricted". The relative frequency for group (3) is low at a value of 0.02204 .

Safe zones were estimated for all combinations of factors used in this experiment and the safe zones were specified in terms of the longitudinal distance from the leader. The sizes (longitudinal distances) of the safe zones vary with the combinations of factors used in the experiment. Results of this experiment suggest that by maintaining the proper longitudinal distance, that is, staying within the "safe zone", the aircraft will not likely experience any wake vortex encounters. 


\section{References}

${ }^{1}$ Hammer, J., "Study of the Geometry of a Dependent Approach Procedure to Closely Spaced Parallel Runways," Proceedings of the IEEE $18^{\text {th }}$ Digital Avionics Systems Conference, IEEE Press, New York, 1999, pp. 4.C.3-1.

${ }^{2}$ Stone, R., "Paired Approach Concept," NASA Langley Parallel Runway Workshop, October 29, 1996.

${ }^{3}$ Landry, S., and Pritchett, A. R., "The Safe Zone for Paired Closely Spaced Parallel Approaches: Implications for Procedures and Automation," Proceedings of the Digital Avionics Systems Conference (DASC00), IEEE Press, New York, 2000 , pp. 3.E.-1.

${ }^{4}$ Bone, R., Olmos, O., and Mundra, A., "Paired Approach: A Closely Spaced Parallel Runway Approach Concept," Proceedings of Eleventh Biennial International Symposium on Aviation Psychology, Columbus, OH, March 2001.

${ }^{5}$ www.atsi.aero

${ }^{6}$ Proctor, F. H., and Hamilton, D. W., "Evaluation of Fast-Time Wake Vortex Prediction Models," AIAA 2009-344.

${ }^{7}$ Proctor, F.H., "The NASA-Langley Wake Vortex Modeling Effort in Support of an Operational Aircraft Spacing System," 36th Aerospace Sciences Meeting \& Exhibit, 12-15 January 1998, AIAA 98-0589.

${ }^{8}$ Han, J., Lin, Y. -L., Schowalter, D. G., Arya, S. P., and Proctor, F. H., "Large Eddy Simulation of Aircraft Wake Vortices within Homogeneous Turbulence: Crow Instability," AIAA Journal, Vol. 38, No. 2, February. 2000, pp. $292-300$.

${ }^{9}$ Crow, S. C., "Stability Theory for a Pair of Trailing Vortices," AIAA Journal, Vol. 8, No. 12, December 1970, pp. 2172-2179.

${ }^{10}$ Sarpkaya, T., "New Model for Vortex Decay in the Atmosphere," Journal of Aircraft, Vol. 37, No. 1, 2000 , pp. 53-61.

${ }^{11}$ Proctor, F.H., Hamilton, D.W. and Han, J., "Wake Vortex Transport and Decay in Ground Effect: Vortex Linking with the Ground," 38th Aerospace Sciences Meeting \& Exhibit, 10-13 January 2000, AIAA-2000-0757.

${ }^{12}$ www.mathworks.com/products/statistics

${ }^{13}$ www.microsoft.com

${ }^{14}$ www.r-project.org 